\title{
Plano de empreendimento matemática divertida
}

\author{
Recebido em 29.04.2015. Aprovado em 05.05. 2015
}

Avaliado pelo sistema double blind review

\author{
Marlí Ferreira Carvalho \\ marlimat@gmail.com \\ E. E. Prof. Waldemar de Freitas Rosa - Sorocaba - SP
}

\section{Resumo}

As escolas da rede estadual têm sido alvo de grandes projetos que visam à melhoria da aprendizagem e a elevação das notas dos alunos nas avaliações propostas tanto pelo nível federal, como municipal e estadual. Seguindo este modelo de gestão, surgiu a ideia de um projeto multidisciplinar para a Escola Estadual Professor Waldemar de Freitas Rosa, com a oportunidade de utilização da SAI (Sala Ambiente de Informática) da escola, em um espaço de aprendizagem e interação, utilizando-se diferentes tecnologias de informação e comunicação e atendendo a diferentes áreas do conhecimento.

Toda a equipe escolar estará envolvida na implementação do projeto, que visa à melhoria da aprendizagem dos alunos, assim como estimular os professores a promoverem aulas mais interessantes e participativas, através dos diversos recursos que farão parte do ambiente multimídia.

Para a realização deste empreendimento, o valor solicitado ao edital será de $R \$ 31.007,40$, destinados à compra de alguns equipamentos e à realização de alguns reparos na sala que comporá o ambiente multimídia; assim como para despesas correntes, material de consumo e serviços treinamento e manutenção dos equipamentos.

O baixo custo deste empreendimento, assim como a dedicação e criatividade da equipe escolar, já anuncia 0 sucesso do investimento, ao possibilitar transformações positivas não só no ambiente físico escolar, mas principalmente na qualidade do ensino, refletindo-se nos resultados das avaliações da aprendizagem e no prazer de frequentar a escola.

Este empreendimento vem ao encontro do Programa de Melhoria da Aprendizagem nas Escolas através dos projetos Descentralizados da Secretaria do Estado da Educação e da Parceria da FACENS ( Faculdade de Engenharia de Sorocaba), do qual esperamos o apoio financeiro para a realização deste projeto que apresentaremos mais minuciosamente nos próximos capítulos.

Palavras-chaves: Educação. Tecnologias de aprendizagem. Plano de empreendimento. Aprendizagem e interação. 


\section{Contexto da escola}

Identificações da escola

A escola E. E. Prof. Waldemar de Freitas Rosa, localizada em Vila Melges - Sorocaba /SP funciona em período integral e atende os cursos de EF Ciclo I ETI, tendo um total de alunos matriculados: 304 sendo 142 do sexo feminino e 162 do masculino.

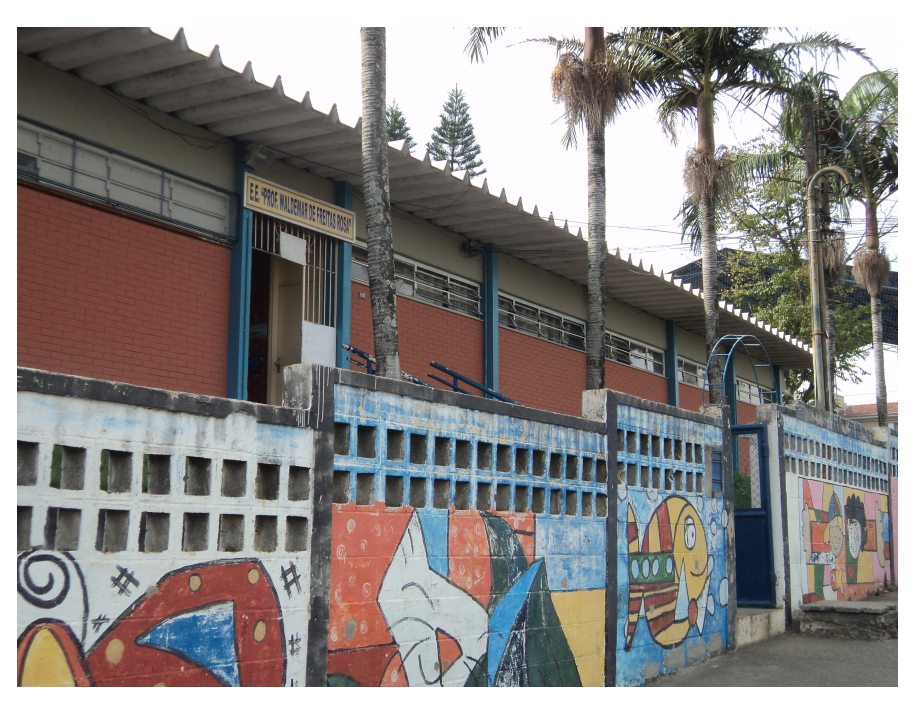

\section{Criação e denominação da Escola}

A escola foi criada com a denominação de "Escola Estadual de Primeiro Grau da Vila Melges" pelo Decreto $n^{0}$ 14.148, publicada no DOE de 27/10/1979 e instalada conforme Resolução SE de 28/05/1980, publicada no DOE de 29/05/1980. Passou a chamar-se EEPG "Prof. Waldemar de Freitas Rosa", com a publicação da lei Federal 9394/96, denominou-se EE "Prof. Waldemar de Freitas Rosa".

\section{Missão}

- $\quad$ Educar e cuidar da construção da imagem positiva do aluno;

- $\quad$ Atender as diferentes necessidades de aprendizagem;

- Promover o sentimento de pertinência e o desenvolvimento de atitudes de compromisso e responsabilidade para com a escola e com a comunidade, instrumentalizando-o com as competência e habilidades necessárias ao desempenho do protagonismo juvenil e à participação social;

- $\quad$ Promover a cultura da paz pelo desenvolvimento de atitudes de auto-respeito, respeito mútuo, solidariedade, justiça e diálogo.

\section{Visão}

Nossa escola está entre as 10 melhores escolas da Diretoria de Ensino de Sorocaba, em 2017 estará entre as 20 melhores escolas classificadas no IDESP, desenvolvendo um ensino de qualidade de modo a ampliar as possibilidades de aprendizagem, com o enriquecimento do currículo básico, a exploração de temas transversais e a vivência de situações que favoreçam o aprimoramento pessoal, social, e cultural de nossos alunos.

\section{Caracterizações da comunidade e clientela}

A EE Prof. Waldemar de Freitas Rosa atende a comunidade de Vila Melges, localizada na Zona Norte de Sorocaba, e também bairros próximos. Em razão de a escola funcionar em período integral, temos poucos alunos matriculados de bairros mais distantes. 
Atendemos 304 crianças em sua maioria carentes da faixa etária de 5,5 anos a 11 anos, pertencentes muitas vezes de famílias não estruturadas, percebendo-se que a maioria das mães trabalha fora, fato que se reflete no reduzido número de comparecimento dos responsáveis pelas crianças às reuniões de pais. Algumas crianças são cuidadas pelos avôs ou por parente próximo. Quanto ao nível de escolaridade $70 \%$ concluíram 0 ciclo I, 18\% concluíram o ensino médio e apenas $3 \%$ nível superior.

Os alunos são matriculados de acordo com a idade, fato que favorece a correta relação idade/série, não havendo grande índice de defasagem neste segmento.

A escola apresenta boa localização, está inserido em um bairro tipicamente residencial da zona norte da cidade de Sorocaba, onde podemos considerá-lo bem estruturado, pois são servidos pelas linhas urbanas de ônibus, orelhões, farmácias, padarias, mercados, açougues e outros serviços que favorecem a comunidade.

Em relação a serviços médicos, há próximo ao bairro um Posto de Saúde e um Pronto Atendimento 24 horas. A escola possui também uma parceria com a Prefeitura dentro do Projeto Escola Saudável.

Não há grande incidência de crimes e problemas de marginalidade.

\section{Grupo gestor}

- Diretor: Marli Ferreira Carvalho - cargo efetivo;

- Vice Diretor: Rosa Mari V. Prestes - professora designada;

- Professor Coordenador: Ivone Vieira da Costa - designada.

\section{Caracterizações do corpo docente}

A equipe docente é composta por 36 professores, sendo 20 que atendem ao Currículo Básico, incluindo dois de Educação Física, três de Arte e um auxiliar. As atividades das Oficinas Curriculares são atendidas pelos professores respectivos todos com formação específica (Letras, Matemática, Artes, Educação Física) ou formação em pedagogia. As oficinas desenvolvidas são: Hora da Leitura, Experiências Matemáticas, Produção de Texto, Atividade Esportivas e Motoras, Orientação de Estudos, Inglês e Atividade Artísticas.

Nossos professores atuantes são comprometidos com o processo de ensino aprendizagem, onde buscam orientações e possuem interesse em participar do projeto de estudo e capacitação oferecidos pela Diretoria de Ensino e pela Secretaria de Estado da Educação.

\section{Características físicas do prédio e dependências da unidade escolar}

A escola está construída em um terreno de $8.218,60 \mathrm{~m}^{2}$, sendo $2.914,08 \mathrm{~m}^{2}$ de área construída e 5.304,52m² de área livre . $O$ terreno é acidentado, com declive moderado, provido com escadarias de sete degraus entre as plataformas térreas para acesso às salas de aula. $O$ acesso de entrada de alunos e 0 acesso ao pátio também há escadas onde foram adaptados rampas e corrimão.

A construção do prédio foi dividida em cinco blocos assim dispostos: Blocos A e B- salas de aula; Bloco C pátio coberto e cozinha; Bloco $\mathrm{D}$ - salas administrativas; Bloco $\mathrm{E}$ - banheiros, depósito de materiais e salas adaptadas. Separados desses blocos, temos à zeladoria e a quadra esportiva.

A capacidade da caixa d'água é de 60.000 litros.

Ambientes pedagógicos: 13 salas de aulas, 1 sala de Leitura, 1 sala Ambiente de Informática com quinze computadores, 1 sala de Vídeo, 1 Quadra Esportiva coberta, 1 Pátio Coberto, 1 espaço para Playground com três brinquedos instalados.

Ambientes administrativos: 1 salão para Refeitório; 1 Cozinha para preparo da merenda e Despensa; 1 WC feminino para alunas com cinco vasos sanitários, um lavatório com três cubas e espelho; 1 WC masculino para alunos com três vasos sanitários, um mictório, um lavatório com três cubas e espelho;1 WC para portadores de necessidades especiais; 1 WC funcionários, 1 WC Adm. Masculino, 1 WC Adm. Feminino, 1 
Depósito de Materiais, 1 Secretaria, 1 Sala do Professor, 1 Sala do Diretor, 1 Sala de Coordenação; 1 Sala de Administração, e 1 casa para Zeladoria.

\section{Identificação do problema ou da oportunidade}

Analisando os resultados das avaliações externas estaduais, federais e internas de nossa escola pudemos observar que nossos alunos possuem grandes dificuldades em Matemática, dado este justificado pela falta de conhecimento, habilidades e gosto pela maior parte dos professores que ministram aulas no ciclo I na rede publica do Estado de São Paulo, com isso eles acabam priorizando mais as atividades de lingua portuguesa, artes, educação física e ao desenvolvimento de atividades que levem a alfabetização que se torna o maior foco neste ciclo.

No início do ano no período de planejamento fizemos as análises dos resultados e montamos oficinas para refletirmos sobre as atividades elencadas nas avaliações e em seguida utilizamos a ferramenta "Os Seis Chapéus de de Bono e Kanbancomo" uma forma de visualizarmos e apontarmos os pontos críticos, os facilitadores, dificuldades, os riscos, as oportunidades entre outros, e com isso começamos a traçar estratégias para minimizar as dificuldades apresentadas pelos alunos nas avaliações de um modo geral.

De posse deste levantamento já somos uma escola de tempo integral desde 2006, nossos alunos entram na escola sete horas onde funciona o período regular e a tarde apartir das 12:10min. Inicia -se o período das oficinas com a utilização de metodologias diferenciadas, significativas e lúdicas.

Segue abaixo resultados das avaliações externas:

\section{- SARESP}

\begin{tabular}{|c|c|c|c|c|}
\hline Ano & Média de Pontos L.P. & Média de Percetual L.P. & Média de Pontos Mat. & Média de Percentual Mat. \\
\hline 2009 & 46,6 & 64,8 & 58,4 & 58,4 \\
\hline 2010 & 58,2 & 80,8 & 73,5 & 73,5 \\
\hline 2011 & 64,0 & 88,9 & 70,7 & 70,7 \\
\hline 2012 & 66,4 & 90,5 & 62,7 & 85,4 \\
\hline
\end{tabular}

\section{- IDESP}

\begin{tabular}{|c|c|c|c|c|}
\hline Ano & Meta & Idesp Escola & L.P. & Mat. \\
\hline 2009 & 4,53 & 4,41 & 5,26 & 3,56 \\
\hline 2010 & 4,53 & 4,43 & 5,07 & 3,8567 \\
\hline 2011 & 4,56 & 6,35 & 7,72 & 4,98 \\
\hline 2012 & 6,39 & 4,78 & 5,238 & 4,36 \\
\hline 2013 & 4,89 & 4,80 & 5,6 & 4,0 \\
\hline
\end{tabular}

Os indicadores nos mostram que estamos evoluindo a cada ano, mas a muito que se trabalhar e de posse destes dados nos reunimos o grupo gestor e corpo docente para elaborar um plano de ação que na prática se tornou o Projeto Matemática Divertida utilizando recursos multimídia, computadores, softwaer de jogos matemáticos com SuperMática, utilização de blocos lógicos, jogos de xadrez, jogos de tabuleiro, jogos de bingo, memória, dominó e para tornar mais atrativo concreto e interativo as aulas a aquisição de lousa digital e projetor wi fi onde pretendemos instalar na sala de informática. 
Pesquisando na rede pública municipal e particular de Sorocaba busquei informações com relação ao uso da lousa digital e tive como devolutiva de professores e colegas diretores que houve um melhora significativa nos resultados das avaliações e consequentemente no redimentos dos alunos, pois eles utilizam este recurso a mais de 4 anos.

Como as mídias estão presentes na vida de todos, nós esperamos que este projeto vise à melhoria da aprendizagem e a elevação das notas dos alunos nas avaliações propostas tanto pelo nível federal, estadual e internas.

Em 2013 desenvolvemos uma parceria com a faculdade de Engenharia Facens onde um professor da oficina de Experiências Matemática faz o curso e por intermédio dele promovemos um Projeto de Robótica na escola, no qual nos motivou e despertou o interesse de dar continuidade agora em 2014, onde os alunos da faculdade irão participar e trabalhar como monitores neste projeto a partir do segundo semestre logo após 0 retorno das férias dos alunos desenvolvendo o conteúdo de matemática com a utilização de mídias e demais materiais descritos nos parágrafo acima.

Os procedimentos e habilidades que precisam ser desenvolvidos são: desenvolver habilidades para resolução de situações problema a partir da interpretação de enunciados orais e escritos, desenvolvendo procedimentos para planejar, executar e checar soluções, raciocinarem, calcular e contar; leitura de tabela e gráficos, comparação entre duas coleções, regularidade do quadro numérico.

Como esta parceria o ano passado trouxe resultados positivos estamos entusiasmados com a implantação deste projeto que será desenvolvido nos próximos 3 anos.

\section{Caracterização do produto / serviço}

\section{Foco do projeto}

O Projeto Multidisciplinar atenderá aos alunos do $3^{\circ} \mathrm{A}$ e $\mathrm{B} ; 4^{\circ} \mathrm{A}$ e $\mathrm{B} ; 5^{\circ} \mathrm{A}, \mathrm{B}, \mathrm{C}$ e $\mathrm{D}$ anos do Ensino Fundamental Ciclo I cujo desenvolvimento das atividades será na SAI (sala de informática) com a utilização de novas e diferentes tecnologias como: computadores, TV, impressoras, telão, Datashow, lousa digital, internet, sites, vídeos, softwares, e-mail, jogos, materiais didáticos e outros recursos como apoio.

\section{Atividades a serem realizadas:}

O desenvolvimento das atividades ocorrerá no período da tarde durante as oficinas de Experiências Matemáticas, Orientação de Estudos e Hora da Leitura e com monitores-alunos do curso de Engenharia da FACENS, que virão a escola duas vezes por semana colaborar com o trabalho dos professores. A SAl será disponibilizada todas as tardes onde haverá uma escala que será organizada pela coordenação da escola em conjunto com os professores de acordo com as atividades propostas utilizando as diferentes mídias acima elencadas, atendendo as 8 turmas semanalmente, em horários fixos. Os alunos poderão utilizar a SAI para realizar atividades de estudo e pesquisa nos horários de intervalo, almoço e após o término das aulas, onde 0 professor auxiliar estará à disposição para eventuais dúvidas e necessidades.

Com a utilização de recursos tecnológicos esperamos despertar em nossos alunos o gosto pela Matemática pois a utilização de mídias e tecnologias de um modo geral tornam o conteúdo mais interativo, significativo, atrativo e motivador, facilitando o desenvolvimento de competências e habilidades.

Este projeto tem como objetivo melhorar o desempenho dos alunos, utilizando novas estratégias de modo a levar 0 aluno a sentir-se seguro para construir conhecimentos matemáticos, estimulando e interagindo com seus pares de forma cooperativa na busca de soluções-problema, respeitando seus modos de pensar e aprendendo com eles. A educação integral entendida enquanto formação integral é a concepção mais comumente encontrada e empregada. Nela, o sujeito é compreendido 
“... em sua condição multidimensional, não apenas na sua dimensão cognitiva, como também na compreensão de um sujeito que é sujeito corpóreo, tem afetos e está inserido num contexto de relações. Isso vale dizer a compreensão de um sujeito que deve ser considerado em sua dimensão biopsicossocial." (Gonçalves, 2006, p.2-3).

\section{Esquema representativo - PROJETO MULTIDISCIPLINAR}

\section{- Matemática Divertida}

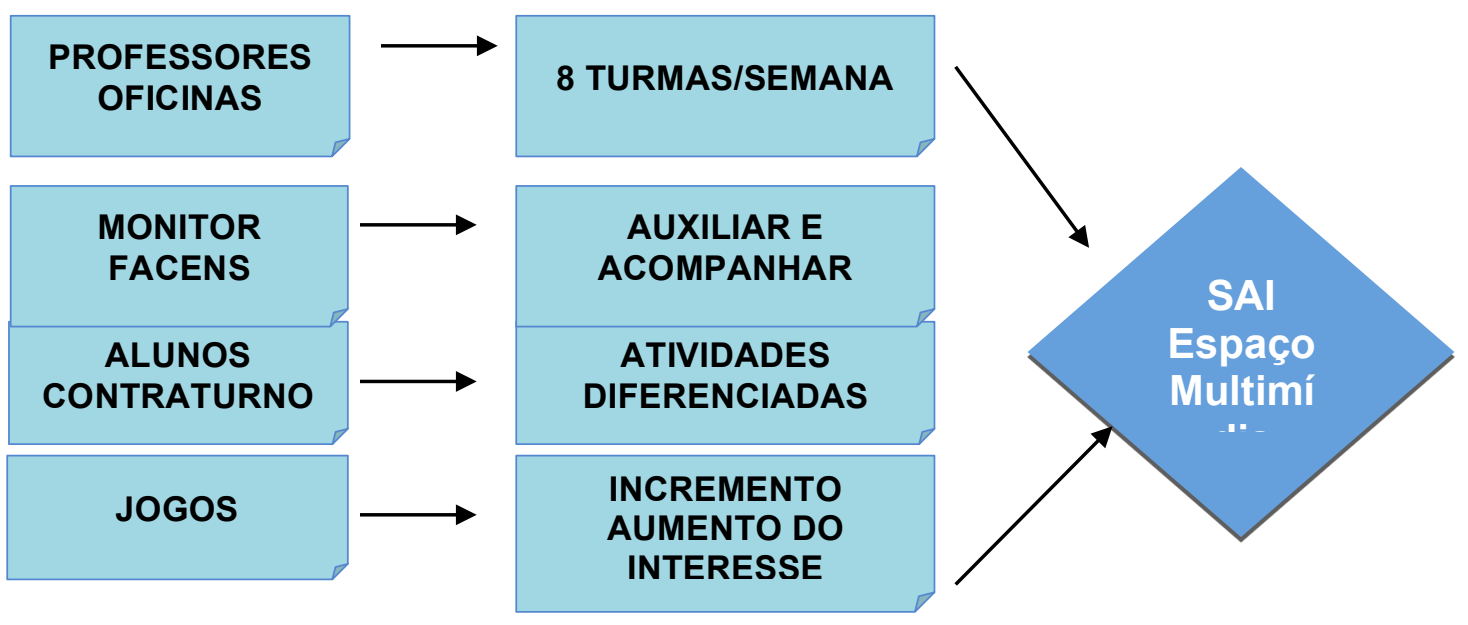

\section{Exemplo de caso de sucesso}

Pesquisa feita no Colégio Renascer mostrou que o uso de recursos tecnológicos como: lousa digital, Datashow, computadores entre outros, associada a um projeto elaborado de acordo com as reais dificuldades dos alunos nas avaliações aponta para uma melhora significativa no rendimento dos alunos, promovendo um aprendizado significativo e atrativo. Os professores relataram que a princípio ficaram resistentes na utilização da lousa digital e de outros recursos tecnológicos, pois não dominavam esta mídia mas agora depois de determinado período e após refletirem e acompanhar a evolução da aprendizagem de seus alunos estão convencidos da importância de buscar e utilizar estas tecnologias a seu favor pois facilita bastante o preparo e a prática de ministrar suas aulas.

Os alunos se mostram motivados com o uso e amaneira de seus professores ministrarem as aulas e satisfeitos com a melhora significativa de suas notas nas avaliações, pois como um menino me relator que agora tem mais vontade de ir à escola.

O uso destas novas tecnologias nos fornece um leque de novas possibilidades como:

- $\quad$ Facilidade de retomar o conteúdo, pois o mesmo ao ser alvo pode ser acessado sempre que necessitamos;

- $\quad$ Podemos fazer consultas em momento real (Google);

- Instalar software de matemática;

- $\quad$ Passar vídeos para enriquecer a aula;

- $\quad$ Interação com o conteúdo na tela;

- Utilizar os jogos (bingo, xadrez, memória, tabuleiro, dominó), levando o aluno fazer comparações com o concreto e com o virtual;

- $\quad$ Imprimir em tempo real as atividades desenvolvidas pelos alunos 


\section{Viabilidade e continuidade do projeto}

A Secretaria de educação do Estado de São Paulo e a Diretoria de Ensino de Sorocaba nos fornece apoio com materiais didáticos, software e capacitação através do Centro de estudos e Núcleo Pedagógico da Diretoria de Sorocaba onde os PCNP de Tecnologias e Matemática vão à escola e organizam junto com a equipe gestora da escola oficinas para capacitar os professores como também possui um técnico para nos orientar nas instalações de programas junto a Secretaria de Educação do Estado de São Paulo e também fornece materiais como o EMAI que possui uma nova maneira de ministrar os conteúdos matemáticos. Com o repasse de verbas do PDDE adquirimos materiais como jogos, materiais pedagógicos como sulfite, canetas, tinta para impressoras e também material permanente com Datashow, som, TV, DVD entre outros, que poderão ser realizados em cooperação na lousa, já que a simples projeção das atividades no telão ou no quadro branco não permite o recurso da interação.

Com a nova SAI agora com mais recursos com a aquisição da lousa digital, esta passará a ser um espaço mais interativo, pois como a EE Profo Waldemar de Freitas Rosa é de tempo Integral nossos alunos permanecem 0 dia todo na escola tornando- necessário ampliar as possibilidades de aprendizagem, com 0 enriquecimento do currículo básico, a exploração de temas transversais e a vivência de situações que favoreçam o aprimoramento pessoal, social e cultural dos nossos alunos.

\section{Estratégia de implementação}

\section{Análise SWOT}

\section{Oportunidades}

Melhorar a imagem da escola perante os alunos e comunidade com o uso de tecnologias.

Existência de projetos e materiais fornecidos pela Secretaria de Educação do Estado de São Paulo e Centro de Estudos Pedagógicos de Sorocaba.

Casos de sucesso da Escola Renascer e EE Municipal Flávio Gagliardi.

Possibilidade de parceria com a Faculdade de Engenharia FACENS.

\section{Ameaças}

A mudança nas políticas governamentais (eleição 2014).

Futuras restrições de recursos que não permitam atualizar ou realizar a manutenção adequada dos recursos multimídia (possibilidade de ficarem obsoletos).

Individualismo, vícios e posturas que barram qualquer opção de melhoras.

\section{Forças}

Equipe gestora e corpo docente comprometidos com a missão da escola se mobilizando para oferecer um ensino de qualidade e sanar as dificuldades de aprendizagem dos nossos alunos.

Apoio e confiança da comunidade escolar.

\section{Fraquezas}

Baixa autoestima dos alunos.

Resistência ou receio dos professores em utilizar novas tecnologias.

Medo de perder o controle da situação.

Falta de envolvimento e comprometimento dos pais dos alunos que apresentam as maiores dificuldades de aprendizagem. 


\section{Objetivos estratégicos}

\begin{tabular}{|c|c|c|}
\hline \multicolumn{3}{|c|}{ DEFINIÇÃO DAS ESTRATÉGIAS } \\
\hline Objetivos & Metas & Estratégias \\
\hline $\begin{array}{l}\text { Contribuir para melhora } \\
\text { na aprendizagem e } \\
\text { rendimento dos alunos }\end{array}$ & $\begin{array}{c}\text { Aumentar em } 30 \% \text { o IDESP até } \\
\text { o final do projeto ( } 36 \text { meses) }\end{array}$ & $\begin{array}{l}\text { Identificar os problemas enfrentados pelos alunos; } \\
\text { Dar suporte e estimular o interesse dos estudantes; } \\
\text { Desenvolver atividades extracurriculares que } \\
\text { reforcem a relação do aluno com a escola. }\end{array}$ \\
\hline $\begin{array}{l}\text { Oferecer um ambiente } \\
\text { atrativo e prazeroso com } \\
\text { a implantação da SAI na } \\
\text { escola }\end{array}$ & $\begin{array}{c}\text { Tornar as aulas mais } \\
\text { interessantes e significativas e } \\
\text { alcançar um aumento em } 10 \% \\
\text { no } \\
\text { desempenho escolar }\end{array}$ & $\begin{array}{c}\text { Capacitar professores ,monitores para uso das } \\
\text { novas tecnologias despertando a criatividade e } \\
\text { gosto com esta nova maneira de ministrar as aulas. }\end{array}$ \\
\hline
\end{tabular}

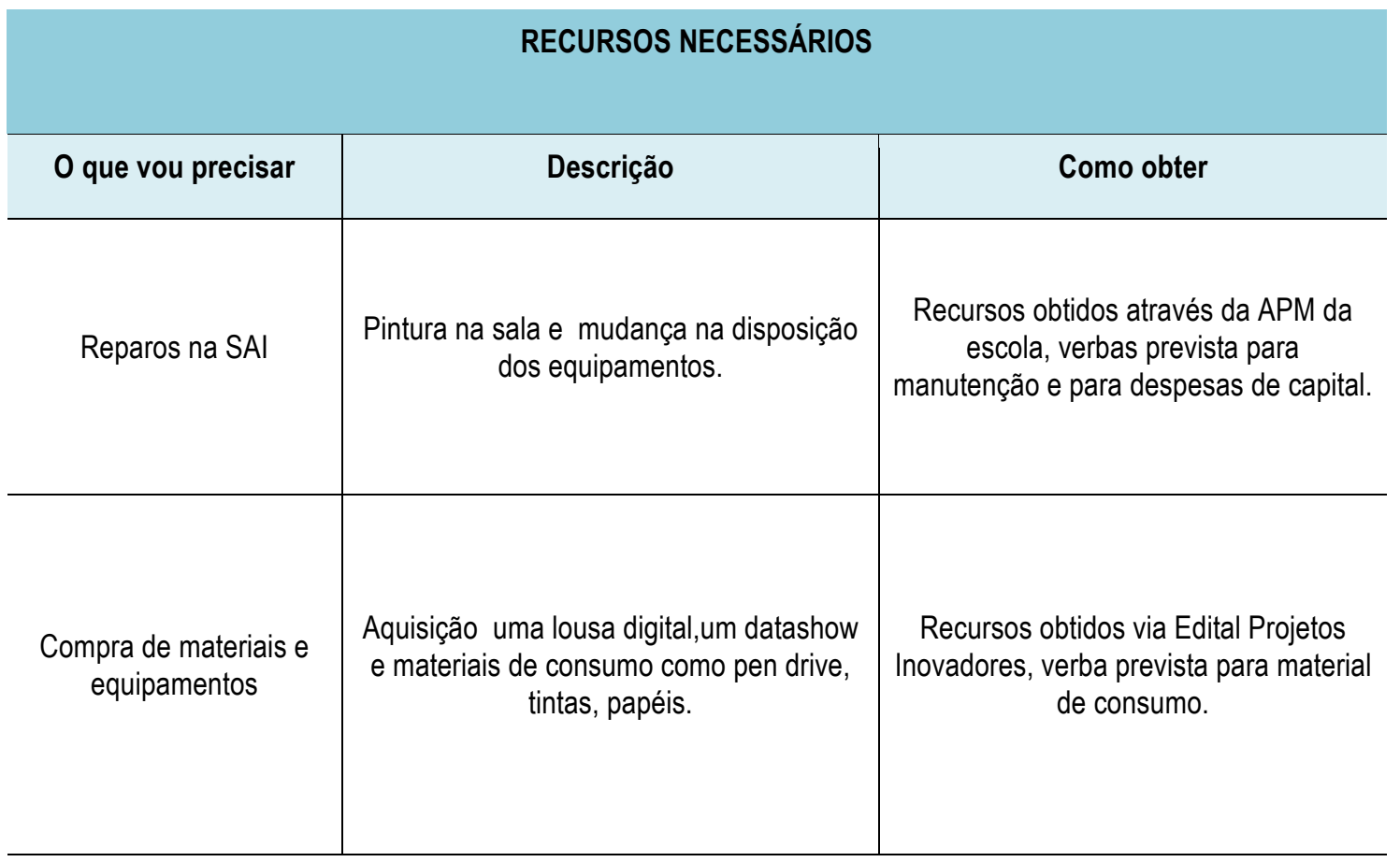




\section{Marketing e comunicação}

A comunicação do Projeto Multidisciplinar, que será implementado no segundo semestre de 2014, iniciará com um marketing integrado, onde o grupo gestor fará a difusão sobre o novo ambiente de aprendizagem para toda a comunidade escolar durante uma celebração no espaço refeitório da unidade escolar no período de replanejamento do calendário escolar que será em Julho de 2014, com o objetivo de que toda a organização se volte para o sucesso e divulgação do projeto. Para isso pretendemos estimular o empenho e o comprometimento de todos com capacitações, organização de oficinas e a criação de espaços e momentos que propiciem a reflexão e diálogo entre todos Posteriormente serão feitas reuniões com os pais e alunos, com o objetivo de lhes informar sobre como será utilizado e organizado todo o trabalho inclusive sobre a nova ferramenta de trabalho que será disponibilizada.

O projeto foi elaborado em prol da comunidade escolar e estamos bastante confiantes, pois acreditamos que terá ótima aceitação pelos clientes (internos e externos), podendo propagar-se por si só, pois irá atender às necessidades e desejos, além de beneficiar tanto a organização quantos aos clientes, nossos alunos.

\section{Modelo de negócios}

A seguir segue representação do modelo de negócios do projeto. 0 intuito é mostrar como a escola se organiza para gerar valor.

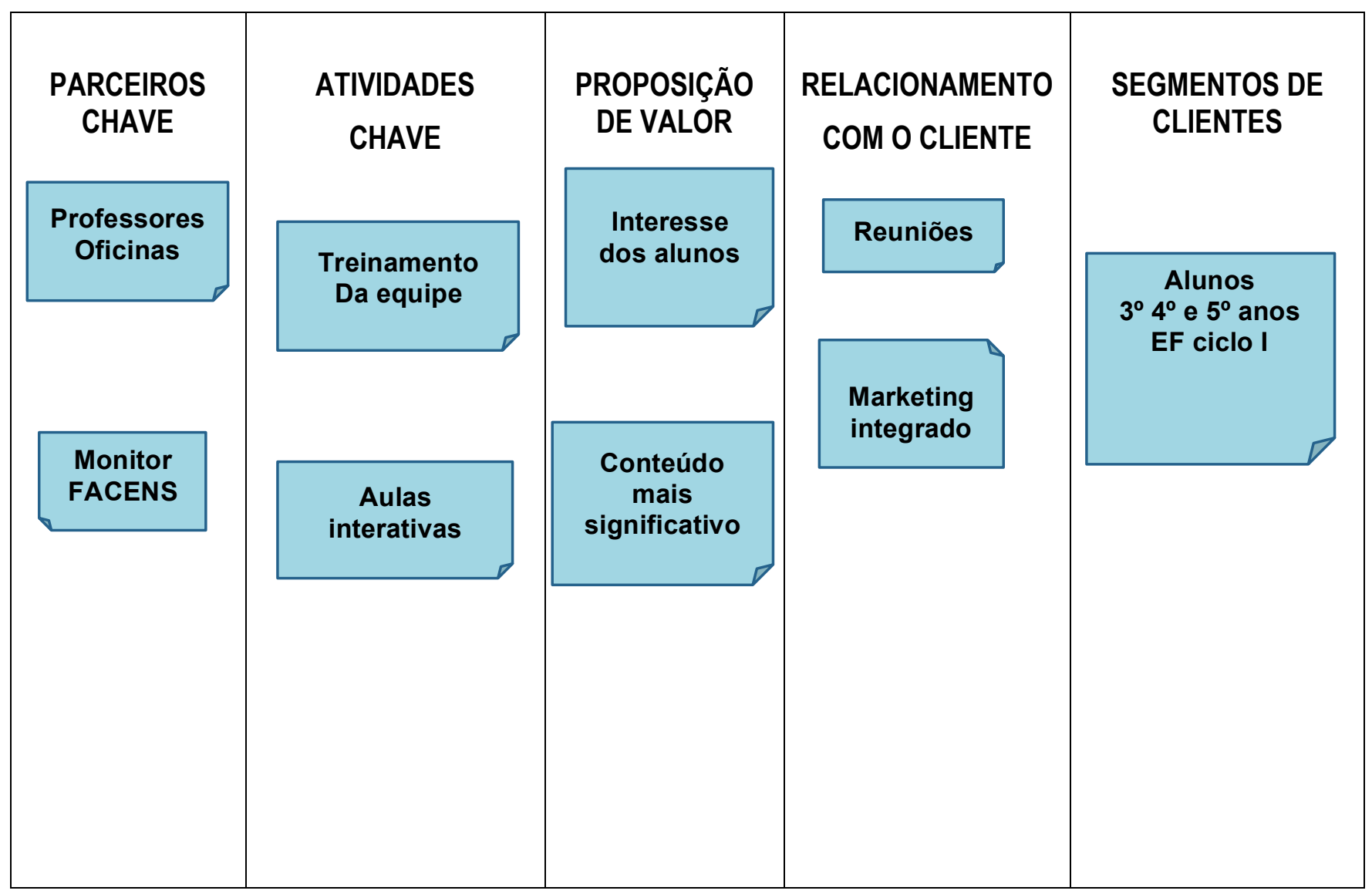




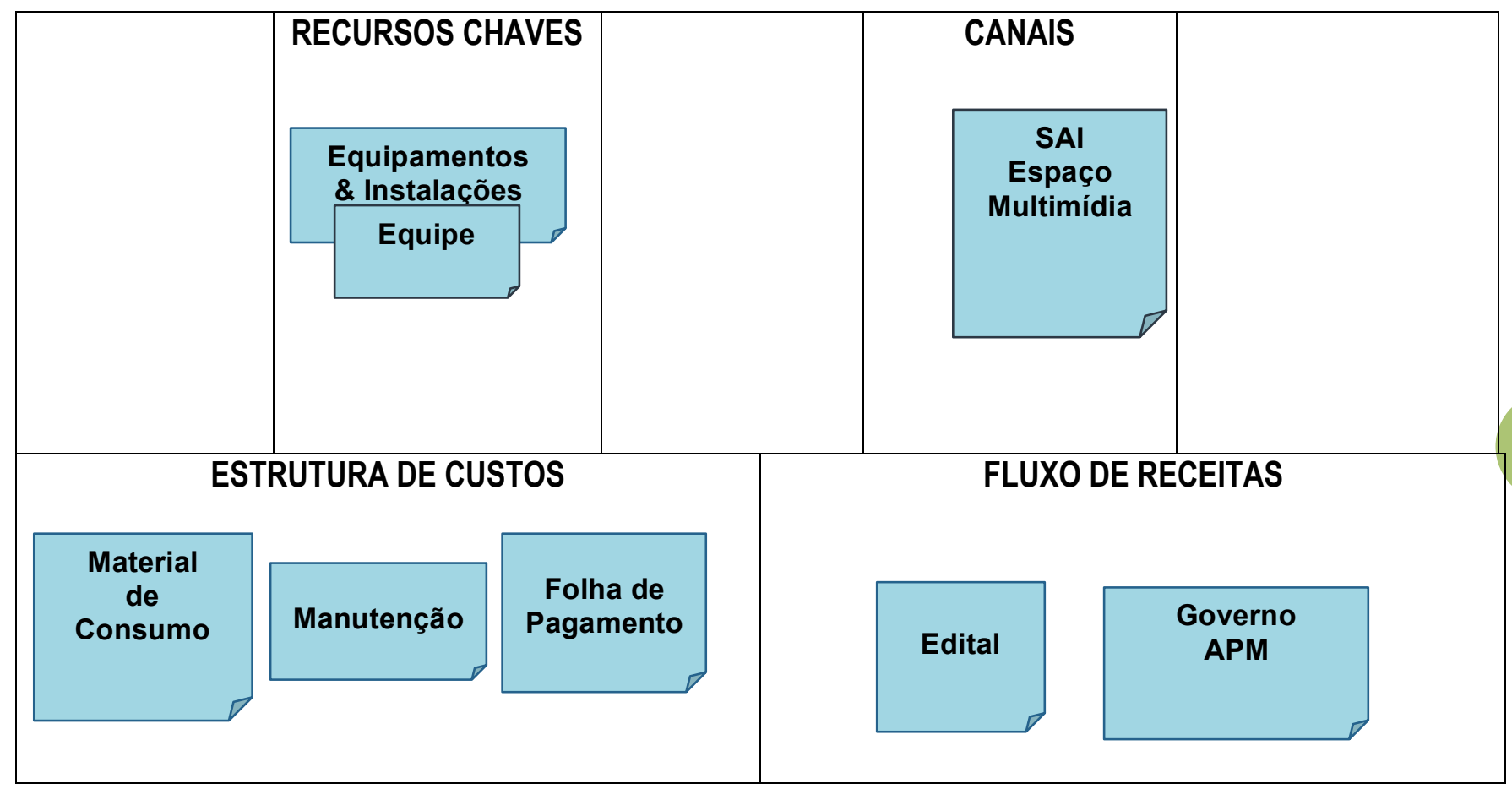

Organização e gerência do empreendimento

\section{Equipe gestora}

A organização e gerência do empreendimento será feita pela equipe gestora, que encontra-se capacitada para executar os projetos idealizados para a escola, contando com a ajuda da sua equipe escolar, como mostra a tabela a seguir:

\begin{tabular}{|c|c|c|c|}
\hline NOME & FUNÇÃO & FORMAÇÃO/ EXPERIÊNCIA & $\begin{array}{l}\text { PRINCIPAIS ATIVIDADES } \\
\text { (NO PROJETO) }\end{array}$ \\
\hline Marli & Diretor & $\begin{array}{l}\text { Cursando em } 2014 \text { MBA Gestão Empreendedora } \\
\text { em Educação. Desempenha a função há mais de } \\
6 \text { anos. }\end{array}$ & $\begin{array}{l}\text { Gestora responsável pela tomada de preços, } \\
\text { orçamentos e prestação de contas das verbas } \\
\text { destinadas à escola. }\end{array}$ \\
\hline Rosa & Vice Diretor & 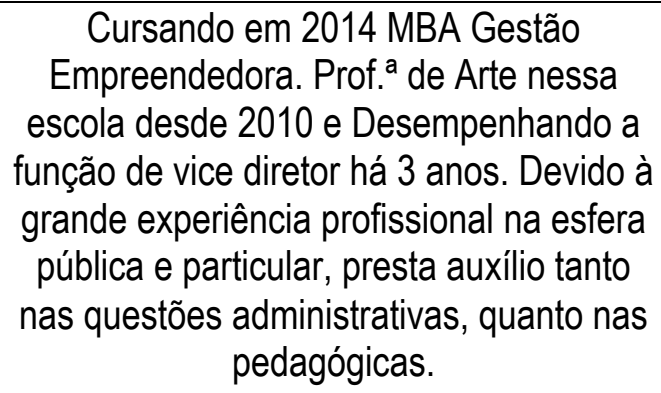 & $\begin{array}{c}\text { Planejar, executar e controlar o } \\
\text { projeto. Elaborar os horários de } \\
\text { utilização da sala para realização do } \\
\text { projeto multidisciplinar, marcar reunião } \\
\text { de divulgação do projeto com a equipe } \\
\text { escolar e os pais. Fazer o controle da } \\
\text { utilização da sala visando à } \\
\text { aprendizagem dos alunos. }\end{array}$ \\
\hline
\end{tabular}




\begin{tabular}{|c|c|c|c|}
\hline Ivone & $\begin{array}{c}\text { Coordenadora } \\
\text { Pedagógica }\end{array}$ & 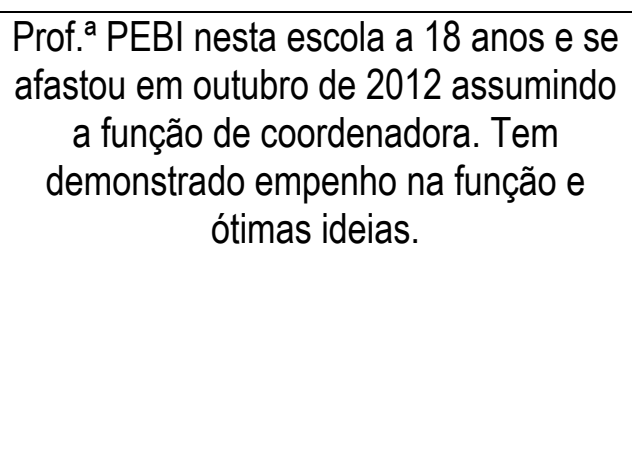 & $\begin{array}{c}\text { Preparar a capacitação dos } \\
\text { professores e realizá-la durante os } \\
\text { ATPCs, sugerindo atividades e } \\
\text { aproveitamento dos equipamentos } \\
\text { disponíveis para a aprendizagem dos } \\
\text { alunos. } \\
\text { Responsável pela capacitação dos } \\
\text { professores para a execução do } \\
\text { projeto. }\end{array}$ \\
\hline
\end{tabular}

\section{Principais Processos}

A tabela a seguir, mostra o perfil da equipe e os principais processos de trabalho necessários para a realização do empreendimento:

\begin{tabular}{|c|c|c|}
\hline PROCESSOS DO SEU EMPREENDIMENTO & COLABORADOR & PERFIL NECESSÁRIO \\
\hline $\begin{array}{l}\text { Responsabilizar-se pelo ambiente multimídia; } \\
\text { realizar atividades com as turmas e receber os } \\
\text { alunos para pesquisas no contraturno. }\end{array}$ & $\begin{array}{l}\text { Anderson (Professor da } \\
\text { Oficina Experiências } \\
\text { Matemáticas) }\end{array}$ & $\begin{array}{l}\text { Conhecimento: Professor titular, na escola a } 2 \\
\text { anos e cursa Engenharia da Computação na } \\
\text { FACENS. } \\
\text { Habilidade: Boa comunicação e desenvolve } \\
\text { ótimo trabalho com os alunos. } \\
\text { Atitude: Domínio de classe, criatividade, } \\
\text { responsabilidade e ética profissional. }\end{array}$ \\
\hline $\begin{array}{l}\text { Utilizar ambiente multimídia para realização de } \\
\text { diferentes atividades nas diversas áreas do } \\
\text { conhecimento. }\end{array}$ & $\begin{array}{l}\text { Equipe de professores da } \\
\text { U.E. e monitores da Facens }\end{array}$ & $\begin{array}{l}\text { Conhecimento: Professores concursados, } \\
\text { experientes e dedicados aos projetos } \\
\text { desenvolvidos na escola. } \\
\text { Habilidade: Gostam de inovação e de ensinar de } \\
\text { diferentes formas. } \\
\text { Atitude: Domínio de classe, criatividade, } \\
\text { responsabilidade com a aprendizagem e } \\
\text { cumprimento de metas. }\end{array}$ \\
\hline
\end{tabular}




\section{Marlí Ferreira Carvalho}

\begin{tabular}{|c|c|c|}
\hline $\begin{array}{c}\text { Confeccionar materiais para as reuniões de } \\
\text { divulgação do projeto, digitar os horários e afixar } \\
\text { nos murais. }\end{array}$ & Lúcia (Gerente) & $\begin{array}{l}\text { Conhecimento: Funcionária a } 20 \text { anos nesta } \\
\text { escola; possui capacitações na CRE para } \\
\text { exercer a função. } \\
\text { Habilidade: domina os processos necessários a } \\
\text { sua função. } \\
\text { Atitude: Autonomia, agilidade, organização e } \\
\text { responsabilidade }\end{array}$ \\
\hline $\begin{array}{c}\text { Garantir a limpeza da sala e manutenção dos } \\
\text { equipamentos }\end{array}$ & Lourdes e Margarida & $\begin{array}{l}\text { Conhecimento: Concursadas para exercer a } \\
\text { função de agente de serviços. } \\
\text { Habilidade: ser cuidadosa ao manusear os } \\
\text { equipamentos que compõem o ambiente } \\
\text { multimídia. Serão capacitadas para limpá-los } \\
\text { corretamente. } \\
\text { Atitude: Gosto em manter organizado o ambiente } \\
\text { para o bem- estar dos alunos. }\end{array}$ \\
\hline
\end{tabular}

\section{Legenda:}

\begin{tabular}{|l|l|}
\hline & Processo Pedagógico \\
\hline & Processo Administrativo \\
\hline & Processo de Apoio \\
\hline
\end{tabular}

\section{Plano Financeiro}

\section{Investimento (despesa de capital)}

\begin{tabular}{|c|c|c|c|}
\hline ITEM & AN01 & AN02 & AN03 \\
\hline Obras & $5.685,70$ & 0,00 & \\
\hline Instalações & $5.685,70$ & & 0,00 \\
\hline Material permanente & & 0,00 & \\
\hline Lousa digital & $9.418,00$ & & \\
\hline Projetor Wi-Fi & $6.018,00$ & & 0,00 \\
\hline Total & $3.400,00$ & $15.503,70$ & 0,00 \\
\hline
\end{tabular}

\section{Detalhamento:}

- Lousa digital Interativa - Ebeam Edge Wireless Luidia com instalação incluída;

- Projetor Wi-Fi Sony VPL-DX125.XGA, 2600 Lumens, conexão para PC,DVD; 
- Parte da obra na sala que comporá o ambiente multimídia - Será feita a colocação de bancadas e pintura das parede e teto. A obra será realizada no mês de julho (recesso escolar).

\section{Despesas correntes}

\begin{tabular}{|c|c|c|c|}
\hline \multicolumn{4}{|c|}{ PROJEÇÃO DAS DESPESAS CORRENTES } \\
\hline Material de Consumo & Total ANO 1 & Total ANO 2 & Total ANO 3 \\
\hline Papel sulfite & $2.185,90$ & $2.603,50$ & $2.586,30$ \\
\hline CDs & 420,00 & 464,00 & 502,00 \\
\hline Pen drive & 502,00 & 0,00 & 0,00 \\
\hline Total & $3.107,90$ & $3.067,50$ & $3.088,30$ \\
\hline \multirow[t]{2}{*}{ Passagens e Locomoção } & Total ANO 1 & Total ANO 2 & Total ANO 3 \\
\hline & 0,00 & 0,00 & 0,00 \\
\hline Total & 0,00 & 0,00 & 0,00 \\
\hline Serviço de Terceiros & Total ANO 1 & Total ANO 2 & Total Ano 3 \\
\hline Treinamento para lousa digital & $1.100,00$ & $1.100,00$ & $1.100,00$ \\
\hline Manutenção dos equipamentos & 980,00 & 980,00 & 980,00 \\
\hline Total & $2.080,00$ & $2.080,00$ & $2.080,00$ \\
\hline Total das Despesas Correntes & $5.187,90$ & $5.147,50$ & $5.168,30$ \\
\hline
\end{tabular}

Detalhamento:

- Papel Sulfite A4 - 15 resmas por mês (equivalente a uma resma por turma);

- CDs - 18 CDs por mês (para arquivamento das atividades do Projeto realizadas com cada turma no Ambiente Multimídia);

- Pen drive - 1 por professor (incluindo Oficina Hora da Leitura, Orientação de Estudos, Experiências Matemática e Monitor FACENS), para planejamento de atividades a serem realizadas com alunos.

Obs.: Alguns materiais didáticos que serão utilizados com os alunos serão fornecidos pelo Núcleo Pedagógico de Diretoria de Ensino de Sorocaba e Secretaria de Educação do Est. São Paulo (tanto os impressos, como os cadernos e livros pedagógicos, quanto os virtuais, como os da Supermática), e os demais serão baixados pela internet sem custo (jogos, vídeos, reportagens, notícias, mapas, revistas eletrônicas, músicas, entre outros).

\section{Despesas administrativas e de pessoal}

*Valor utilizado como contrapartida

\begin{tabular}{|l|c|c|c|}
\hline \multicolumn{3}{|c|}{ PROJEÇÃO DAS DESPESAS ADMINISTRATIVAS E DE PESSOAL } \\
\hline Administrativas & Total AN0 1 & Total AN0 2 & Total AN0 3 \\
\hline Energia elétrica & $3.700,00$ & $3.774,00$ & $3.849,48$ \\
\hline
\end{tabular}


Marlí Ferreira Carvalho

\begin{tabular}{|c|c|c|c|}
\hline \multicolumn{1}{|c|}{ Material de divulgação } & 700,00 & 714,00 & 728,28 \\
\hline Total & & & $4.577,76$ \\
\hline Pessoal & $4.400,00$ & $4.488,00$ & Total ANO 3 \\
\hline Vice-Diretor & Total ANO 1 & Total ANO 2 & 578,92 \\
\hline Diretor & 904,16 & 578,92 & 281,04 \\
\hline Coordenadora Pedagógica & 301,72 & 281,04 & $1,131,52$ \\
\hline Profissional de SAl & $1.131,52$ & $1.131,52$ & $9.688,40$ \\
\hline Total & $9.688,40$ & $9.688,40$ & $11.679,88$ \\
\hline Total das Despesas Adm+Pessoal & $10.894,28$ & $11.909,88$ & $16.257,64$ \\
\hline
\end{tabular}

\section{Necessidade de recursos}

\begin{tabular}{|c|c|c|c|c|}
\hline \multicolumn{4}{|c|}{ CÁLCULO DA NECESSIDADE DE RECURSOS } & \multirow[b]{2}{*}{ TOTAL } \\
\hline Item & ANO 1 & ANO 2 & ANO 3 & \\
\hline I. Total das Despesas Correntes & $5.187,30$ & $5.147,50$ & $5.168,30$ & \multirow[t]{2}{*}{$15.503,70$} \\
\hline Material de Consumo & $3.107,90$ & $3.067,50$ & $3.088,30$ & \\
\hline Passagens e Despesas com Locomoção & 0,00 & 0,00 & 0,00 & $9.263,70$ \\
\hline Serviços de Terceiros & $2.080,00$ & $2.080,00$ & $2.080,00$ & $\begin{array}{c}0,00 \\
6.240,00\end{array}$ \\
\hline II. Total de Despesas Administrativas & $4.400,00$ & $4.488,00$ & $4.577,76$ & \multirow[t]{2}{*}{$13.465,76$} \\
\hline III. Total de Despesas com Pessoal & $10.894,28$ & $11.909,88$ & $11.679,88$ & \\
\hline IV. Total de despesas de Capital & $15.503,70$ & 0,00 & 0,00 & $\begin{array}{r}34.484,04 \\
15.503,70\end{array}$ \\
\hline Necessidade Recursos (I+||+|II+IV) & $36.743,20$ & $20.577,88$ & $20.814,76$ & $78.957,20$ \\
\hline Recursos Edital & $20.754,40$ & $4.984,00$ & $5.135,20$ & $31.007,40$ \\
\hline Recursos da Organ. (contrapartida) & $16.702,80$ & $16.279,78$ & $16.164,22$ & $47.949,80$ \\
\hline
\end{tabular}




\section{Validações}

\begin{tabular}{|c|c|c|c|}
\hline ITENS FINANCIÁVEIS & $\begin{array}{c}\text { VALORES } \\
\text { CONSOLIDADOS }\end{array}$ & VALIDAÇÃO \\
\hline $\begin{array}{c}\text { Despesas Correntes } \\
\text { Despesas de Capital (máximo de 50\% do } \\
\text { projeto) }\end{array}$ & $15.503,70$ & $50 \%$ & ok: $=50 \%$ \\
\hline $\begin{array}{c}\text { Total de Recursos Solicitados } \\
\text { Contrapartida }\end{array}$ & $31.007,40$ & $100 \%$ & ok: $<90$ mil \\
\hline Valor total da contrapartida & $47.949,80$ & Valor total da contrapartida & $47.949,80$ \\
\hline $\begin{array}{c}\text { Valor solicitado ao edital pelo projeto } \\
\text { Percentual: contrapartida/ recursos } \\
\text { solicitados }\end{array}$ & $31.007,40$ & $\begin{array}{c}\text { Valor solicitado ao edital pelo } \\
\text { projeto }\end{array}$ & $31.007,40$ \\
\hline
\end{tabular}

